\title{
APLIKASI MULTIMEDIA TERJEMAHAN SURAH YASIN DALAM BAHASA JAWA MENGGUNAKAN BAHASA PEMROGRAMAN LINGO
}

\author{
Moh. Ali Ridho ${ }^{1}$ Arini $^{2}$, Bakrie La Katjong ${ }^{3}$ \\ ${ }^{1,2,3}$ Program Studi Teknik Informatika \\ Fakultas Sains dan Teknologi \\ Universitas Islam Negeri Syarif Hidayatullah Jakarta \\ ${ }^{1}$ contact.aliridho@gmail.com, ${ }^{2}$ arini@uinjkt.ac.id
}

\begin{abstract}
Abstrak - Surah Yasin adalah salah satu surah dalam Al-Qur'an yang sudah umum dibaca dihampir di setiap pengajian atau di kegiatan keagamaan Islam lainnya sebagai bacaan utama. Berdasarkan data sensus penduduk tahun 2010 dari Badan Pusat Statistik RI, pemeluk agama Islam di daerah Jawa mencapai $62 \%$ dan yang terbanyak diantara daerah-daerah lain di Indonesia. Dari hasil wawancara dengan bapak Dr. Suwendi selaku kepala Seksi Ketenagaan Subdit Pendidikan Diniyah dan Pondok Pesantren Kemeneterian Agama RI menyatakan bahwa penyebaran pendidikan Al-Qur'an kepada masayarakat Islam di daerah Jawa masih sangat minim dan juga belum ada metode pembelajaran pendidikan Islam yang menggunakan bahasa Jawa sebagai bahasa utama dalam metode pengajarannya. Oleh karenanya pembuatan aplikasi terjemahan surah Yasin ke dalam bahasa Jawa diharapkan dapat menarik minat generasi muda untuk kembali membudayakan bahasa Jawa dan memberi pemahaman lebih bagi umat Islam di Jawa dalam memahami surah-surah dalam Al-Qur'an, khususnya surah Yasin. Dalam penelitian ini, menggunakan metode studi pustaka, wawancara dan kuesioner dalam pengumpulan data. Pengembangan sistem mengguanakan metode Multimedia Development Life Cycle dari Luther dimana tahapannya adalah konsep (concept), perancangan (design), pengumpulan bahan (material collecting), pembuatan (assembly), pengujian (testing) dan distribusi (distribution). Dari penelitian ini dihasilkan aplikasi multimedia terjemahan surah Yasin ke dalam bahasa Jawa dan hasil aplikasi disebarkan melalui pihak Kemenag RI serta diunggah di website file sharing. Disarankan untuk penelitian selanjutnya agar ditambahkan database surah-surah lain dalam Al-Qur'an lengkap dengan tafsirnya, penambahan kosakata kamus, perlu adanya rancangan aplikasi berbasis smartphone dan peningkatan algoritma yang digunakan pada fitur kamus. Tools yang digunakan dalam pembuatan aplikasi ini diantaranya software Adobe Director, Adobe Photoshop, Adobe Flash dan Arca Database Browser. Kata kunci: Bahasa Jawa, Multimedia Interaktif, Source Lingo, Surah Yasin
\end{abstract}

\section{PENDAHULUAN}

\section{A. Latar Belakang}

Membahas jumlah penduduk Indonesia yang memeluk agama Islam, saat ini terdapat 207.176.162 atau sekitar $87,18 \%$ dari jumlah penganut agama lainnya di Indonesia. Jika dilihat berdasarkan wilayah, sebagian besar penganut agama Islam tinggal di propinsi-propinsi di Jawa (62\%). Sebanyak $20,2 \%$ penganut agama Islam tinggal di propinsi Jawa Barat, propinsi Jawa Timur 17,4\% dan propinsi Jawa Tengah 15,1\% (Data Sensus Penduduk 2010, Badan Pusat Statistik RI).

Dengan banyaknya masyarakat di Jawa yang memeluk agama Islam dapat dipastikan jika pendidikan yang berhubungan dengan agama Islam sudah menjadi suatu keharusan di daerah Jawa. Akan tetapi, yang menjadi masalah adalah masih banyaknya suku atau masyarakat Jawa yang masih tertinggal pendidikan atau pengetahuannya.

Dengan semakin berkembangnya teknologi seperti saat ini, umat Islam di Indonesia, khususnya yang tinggal di pulau Jawa dan menggunakan bahasa Jawa dalam kegiatan sehari-hari seharusnya dapat lebih mudah dalam melakukan hal keagamaan. Contoh paling sederhana adalah ketika membaca atau mempelajari Al-Quran, baik itu surah Yasin atau surah-surah yang lainnya akan semakin mudah jika disertai terjemahan dalam bahasa Jawa. Sehingga anjuran membaca Al-Quran, khususnya surah Yasin tidak hanya dikarenakan menambah pahala serta amal ibadah, akan tetapi juga dapat mempelajari dan mengamalkan makna yang terkandung di dalamnya.

\section{B. Perumusan Masalah}

Ditinjau dari latar belakang masalah di atas, rumusan masalah penelitian ini adalah bagaimana merancang aplikasi multimedia terjemahan surah Yasin ke dalam bahasa Jawa dan mendistribusikannya kepada masyarakat ?

a. Batasan Masalah

a) Surah yang ditampilkan dalam aplikasi ini hanya surah Yasin.

b) Bahasa pemrograman yang digunakan hanya bahasa pemrograman Lingo. 
c) Tools yang digunakan terdiri dari : Adobe Director, Adobe Flash, Adobe Photoshop dan Arca Database Browser.

d) Konten yang digunakan terdiri dari gambar, teks, audio dan animasi.

e) Sumber terjemahan surah Yasin dalam bahasa Jawa diambil dari modul Al-Qur'an dan terjemahan bahasa Jawa surah Yaasiin DEPAG RI.

b. Tujuan dan Manfaat

a. Tujuan

Berdasarkan rumusan masalah penelitian di atas dapat diketahui tujuan dari penelitian ini adalah menghasilkan aplikasi multimedia terjemahan surah Yasin ke dalam bahasa Jawa yang dapat menarik minat generasi muda untuk kembali membudayakan bahasa Jawa dan mendistribusikannya kepada masyarakat.

b. Manfaat

1) Mempermudah pengguna aplikasi khususnya masyarakat Jawa untuk memahami Surah Yasin dan terjemahannya dalam bahasa Jawa.

2) Sebagai media yang dapat membantu mengembangkan kualitas beragama Islam bagi masyarakat di Jawa.

3) Sebagai metode lain dalam penyebaran informasi.

c. Metodologi Penelitian

Menggunakan Metode Penegumpulan Data dan Metode Pengembangan Sistem

\section{LANDASAN TEORI}

\section{A. Aplikasi}

Aplikasi adalah Instruksi-instruksi (program komputer) yang ketika dijalankan menyediakan fiturfitur, fungsi-fungsi, dan kinerja-kinerja yang dikehendaki (Pressman, 2012:5).

B. Multimedia

Multimedia, ditinjau dari bahasanya, terdiri dari 2 kata, yaitu multi dan media. Multi memiliki arti banyak atau lebih dari satu, sedangkan media merupakan bentuk jamak dari medium juga diartikan sebagai saran, wadah, atau alat (Darma, 2009:6).

Multimedia adalah kombinasi teks, foto, seni grafis, suara, animasi dan elemen-elemen video yang dimanipulasi secara digital (Vaughan, 2006:3).

a. Elemen Multimedia

Multimedia terdiri dari beberapa objek (element), yaitu teks, grafik atau image, animasi, audio, video dan link interaktif (Sutopo, 2003:5).

b. Desain Komunikasi Visual

Desain yang baik sanggup meningkatkan penjualan produk, mengangkat citra perusahaan atau perorangan, mempengaruhi keberhasilan sebuah event dan apa tujuan yang ingin dicapai (Rustan, 2010:16).

c. Desain Layout

Pada dasarnya layout dapat dijabarkan sebagai tataletak elemen-elemen desain terhadap suatu bidang dalam media tertentu untuk mendukung konsep/pesan yang dibawanya. Definisi layout dalam perkembangannya sudah sangat meluas dan melebur dengan definisi desain itu sendiri (Rustan, 2010:2).

a. Surah Yasin

Surat Yasin merupakan surat dalam Al-Qur'an yang ke-36. Surat Yasin ini memiliki ayat hingga 83. Surat yang termasuk ke dalam surat Makkiyah ini diturunkan setelah surat Jin, Diberi nama "Yasin" karena di awali dengan kalimah "Yaa Sin..." seperti pada surat-surat yang lainnya dalam surat Al-Qur'an.

Arti dalam surat Yasin, yaitu berada pada permulaan surat Yasin itu sendiri. Allah telah memberikan pencerahan bahwa setelah kalimat tersebut, akan di sampaikan hal-hal penting. Yaitu penegasan bahwa Nabi Muhammad adalah utusan Allah Swt. Hal tersebut semata-mata untuk memberi peringatan kepada seluruh umat manusia yang belum diberi peringatan pada masa sebelum pemberian penegasan tersebut diturunkan.

Pokok-pokok dalam Surat Yasin berisi mengenai akidah akhlak umat yang hidup sebelum masa Nabi Muhammad SAW, masa-masa perjuangan para Rasul Allah Swt yang menyampaikan risalah-risalah dan juga ajaran-ajaran kenabian, keagungan Allah Swt, dan berbagai perilaku umat manusia.

Dalam riwayat Ibnu Abbas r.a. dan riwayat lainnya menjelaskan tentang pemberian nama surat Yasin. Kalimat Yaa Sin adalah salah satu dari banyaknya pernyataan Allah Swt, nama Allah, nama Al-Qur'an, atau bisa juga nama-nama dari Nabi Muhammad SAW.

\section{Bahasa Jawa}

Bahasa Jawa adalah bahasa yang digunakan penduduk suku bangsa Jawa terutama di beberapa bagian Banten terutama di kabupaten Serang dan Tangerang, Jawa Barat khususnya kawasan Pantai utara terbentang dari pesisir utara Karawang, Subang, Indramayu dan Cirebon, Jawa Tengah \& Jawa Timur di Indonesia.

Tingkat tutur atau ragam halus yaitu Ragam bahasa yang dipakai dalam situasi sosial yang mewajibkan sopan santun. Tingkat tutur dalam bahasa Jawa dibagi menjadi tiga, yaitu tingkat tutur ngoko, tingkat tutur madya dan tingkat tutur karma

Poedjasoedarma berpendapat bahawa tingkat tutur ngoko mencerminkan rasa tak berjarak antara 01 terhadap 02 dan tingkat tutur ini dipakai jika seseorang ingin menyatakan keakrabannya terhadap mitra wicara (02). Tingkat tutur madya diartikan sebagai tingkat tutur menengah antara krama dan ngoko tetapi tetap menunjukkan perasaan sopan meskipun kadar kesopanannya hanya sedang-sedang saja. Tingkat tutur krama diartikan sebagai tingkat tutur yang memancarkan arti penuh sopan santun dan tingkat tutur ini menandakan adanya perasaan segan 01 terhadap 02 (Sasangka 2004:14).

a. Tingkat Tutur Ngoko (Ragam Ngoko) 
Yaitu unggah ungguh bahasa jawa yang berintikan leksikon ngoko. Ciri-ciri katanya terdapat afiks di-, -e dan -ake. Ragam ngoko dapat digunakan oleh mereka yang sudah akrab dan oleh mereka yang merasa dirinya lebih tinggi status sosialnya daripada lawan bicara (mitra wicara). Ragam ngoko mempunyai dua bentuk varian, yaitu ngoko lugu dan ngoko alus (Sasangka 2004:95).

\section{Ngoko Lugu}

Yang dimaksud dengan ngoko lugu adalah bentuk unggah-ungguh bahasa Jawa yang semua kosakatanya berbentuk ngoko dan netral (leksikon ngoko dan netral) tanpa terselip leksikon krama, krama inggil, atau krama andhap, baik untuk persona pertama (01), persona kedua, persona kedua (02), maupun kedua (02), maupun untuk persona ketiga (03).

\section{Ngoko Alus}

Yang dimaksud dengan ngoko alus adalah bentuk unggah-ungguh yang di dalamnya bukan hanya terdiri atas leksikon ngoko dan netral saja, melainkan juga terdiri atas leksikon krama inggil, krama andhap, atau leksikon krama yang muncul di dalam ragam ini sebenarnya hanya digunakan untuk menghormati mitra wicara (orang ke 2 atau 3) (Sasangka 2004:99-100).

b. Tingkat Tutur Krama (Ragam Krama)

Yang dimaksud dengan ragam krama adalah bentuk unggah-ungguh bahasa Jawa yang berintikan leksikon krama, atau yang menjadi unsur inti di dalam ragam krama adalah leksikon krama bukan leksikon yang lain. Afiks yang muncul dalam ragam ini pun semuanya berbentuk krama (misalnya, afiks dipun-, -ipun, dan -aken). Ragam krama digunakan oleh mereka yang belum akrab dan oleh mereka yang merasa dirinya lebih rendah status sosialnya daripada lawan bicara. Ragam krama mempunyai tiga bentuk varian, yaitu krama lugu, karma andhap dan krama alus (Sasangka 2004:104).

1. Krama Lugu / Krama Madya

Secara semantis ragam krama lugu dapat didefinisikan sebagai suatu bentuk ragam krama yang kadar kehalusannya rendah. Meskipun begitu, jika dibandingkan dengan ngoko alus, ragam krama lugu tetap menunjukkan kadar kehalusan (Sasangka 2004:105).

\section{Krama Andhap}

Yaitu bentuk krama yang digunakan untuk menghormati lawan bicara dengan cara merendahkan diri sendiri.

\section{Krama Alus / Krama Inggil}

Yang dimaksud dengan krama alus adalah bentuk unggah-ungguh bahasa Jawa yang semua kosakatanya terdiri atas leksikon krama dan dapat ditambah dengan leksikon krama inggil atau krama andhap. Meskipun begitu, yang menjadi leksikon inti dalam ragam ini hanyalah leksikon yang berbentuk krama. Leksikon madya dan leksikon ngoko tidak pernah muncul di dalam tingkat tutur ini. Selain itu, leksikon krama inggil atau krama andhap secara konsisten selalu digunakan untuk penghormatan terhadap mitra wicara. Secara semantis ragam krama alus dapat didefinisikan sebagai suatu bentuk ragam krama yang kadar kehalusannya tinggi (Sasangka 2004:111).

a. Basis Data

Basisdata adalah mekanisme yang digunakan untuk menyimpan informasi atau data. Informasi adalah sesuatu yang kita gunakan sehari-hari untuk berbagai alasan. Dengan basisdata, pengguna dapat menyimpan data secara terorganisasi. Setelah data disimpan, informasi harus mudah diambil. Kriteria dapat digunakan untuk mengambil informasi. Data harus mudah ditambahkan ke dalama basis data, dimodifikasi dan dihapus (Paryudi, 2005:1).

b. Bahasa Pemrograman Lingo

Lingo adalah bahasa pemrograman Director yang berguna untuk menciptakan interaksi antara pemakai dengan movie yang istilah populernya disebut movie interaktif. Lingo terbagi menjadi 4 tipe, yaitu behavior script, movie script, parent script, dan yang terakhir adalah cast member script. Behavior, movie, dan parent scriptakan tampil sebagai cast member yang ada di dalam Cast window. Berikut penjelasan singkat mengenai tipe script yang baru disebutkan di atas (Chandra, 2005:3).

\section{METODOLOGI PENELITIAN}

\section{A. Metode Pengumpulan Data}

a. Studi Lapangan

1) Wawancara

Peneliti melakukan wawancara pada tanggal 2 September 2014 di Kantor Kementrian Agama RI dengan Bapak Dr. Suwendi, selaku Kepala Seksi Ketenagaan Subdit Diniyah Direktorat Pendidikan Diniyah dan Pondok Pesantren Ditjen Pendidikan Islam Kementerian Agama RI.

2) Kuesioner

Peneliti menyebarkan kuisioner kepada para calon pengguna (user) aplikasi terjemahan surah Yasin ke dalam bahasa Jawa.

b. Studi Literatur

Metode pengumpulan kepustakaan atau studi literatur, dilakukan dengan cara membaca buku yang berkaitan dengan surah Yasin, bahasa Jawa, animasi, layouting, database, dan pemrograman berorientasi obyek khususnya pada bahasa lingo.

\section{B. Metode Pengembangan Sistem}

Dalam aplikasi multimedia ini dilakukan tahapan pengembangan multimedia menurut Luther, yaitu Multimedia Development Life Cycle (MDLC) dimana pengembangan aplikasi multimedia dilakukan berdasarkan enam tahap, yaitu: konsep (concept), perancangan (design), pengumpulan bahan (material 
collecting), pembuatan (assembly), pengujian (testing) dan distribusi (distribution).

\section{HASIL DAN PEMBAHASAN}

\section{A. Studi Lapangan}

a. Wawancara

Kurang meratanya penyebaran pendidikan AlQur'an pada masyarakat Jawa yang beragama Islam, pentingnya digitalisasi Al-Quran dalam terjemahan bahasa Jawa, dan menyambut baik rencana pembuatan aplikasi terjemahan surah yasin ke dalam bahasa Jawa.

b. Kuesioner

Masyarakat menganggap penting dilestarikannya kebudayaan berupa digitalisasi terjemahan surah Yasin ke dalam bahasa Jawa, masyarakat menginginkan aplikasi yang berhubungan dengan bahasa Jawa, dan masyarakat tertarik untuk mengganakan aplikasi terjemahan surah yasin ke dalam bahasa Jawa.

B. Konsep (Concept)

Tabel 1. Konsep Aplikasi

\begin{tabular}{|lll|}
\hline Judul & $: \begin{array}{l}\text { Aplikasi Multimedia Terjemahan Surah Yasin } \\
\text { dalam Bahasa Jawa menggunakan Bahasa } \\
\text { Pemrograman Lingo }\end{array}$ \\
\hline Pengguna & $:$ & $\begin{array}{l}\text { Masyarakat yang memahami dan ingin } \\
\text { memahami atau mempelajari bahasa Jawa }\end{array}$ \\
\hline Tujuan & $: \begin{array}{l}\text { Menyimpan aplikasi multimedia terjemahan } \\
\text { surah Yasin ke dalam bahasa Jawa }\end{array}$ \\
\hline $\begin{array}{l}\text { Jenis } \\
\text { Aplikasi }\end{array}$ & $:$ Multimedia \\
\hline Gambar & $: \begin{array}{l}\text { Menggunakan file yang berformat .png dan } \\
\text { jpg yang diambil dari situs internet dan dibuat } \\
\text { oleh peneliti }\end{array}$ \\
\hline Audio & $: \begin{array}{l}\text { Menggunakan file yang diambil dari situs } \\
\text { internet dan diconvert menjadi .wav }\end{array}$ \\
\hline Animasi & $: \begin{array}{l}\text { Animasi dibuat dengan Adobe Flash } \\
\text { menggunakan Grafik 2D berformat .swf }\end{array}$ \\
\hline Font & $: \begin{array}{l}\text { Menggunakan font Arial, Bandy dan } \\
\text { Traditional Arabic }\end{array}$ \\
\hline Warna & $: \begin{array}{l}\text { Mengunakan warna hijau, hitam, jingga, } \\
\text { merah dan putih }\end{array}$ \\
\hline $\begin{array}{l}\text { Software } \\
\text { yang } \\
\text { digunakan }\end{array}$ & $\begin{array}{l}\text { Software yang digunakan adalah Adobe } \\
\text { Director, Adobe Photoshop, Adobe Flash dan } \\
\text { Arca Database Browser }\end{array}$ \\
\hline
\end{tabular}

C. Perancangan (Design)

a. Perancangan Stroyboard

Terdapat 7 storyboard pada perancangan aplikasi ini, diantaranya sebagai berikut : Storyboard Intro, Storyboard Menu Utama, Storyboard Halaman Surah Yasin, Storyboard Halaman Bahasa Jawa, Storyboard Halaman Memilih Ayat Surah Yasin, Storyboard Halaman Terjemahan Ayat Surah Yasin dan Storyboard Halaman Kamus

b. Perancangan Struktur Navigasi

Struktur Navigasi ini berguna untuk memberikan gambaran link dari halaman satu ke halaman lainnya.

c. Perancangan State Transition Diagram (STD)

STD merupakan diagram yang memodelkan tingkah laku (behaviour) sistem berdasarkan pada definisi satu bagian dari keadaan sistem. Langkah ini digunakan untuk menggambarkan kinerja sistem.

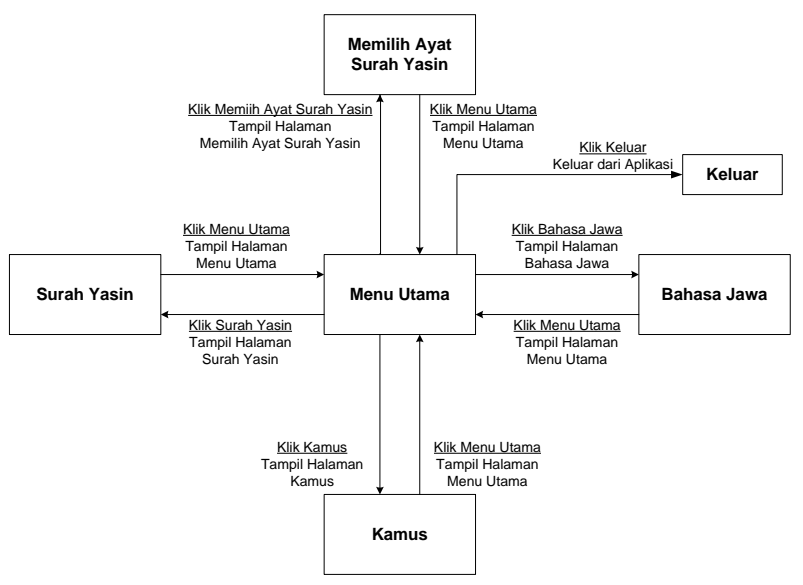

Gambar 1. State Transition Diagram Menu Utama

d. Perancangan Struktur Database

Database diperlukan untuk menempatkan datadata yang bersifat dinamis, dalam artian data-data dapat ditambah, diubah dan dihapus. Penulis merancang sebuah database yang terdiri dari dua tabel untuk menyimpan data.

1) terjemahyasin, untuk menyimpan terjemahan ayat surah Yasin dalam bahasa Jawa dan bahasa Indonesia.

2) kamusjawaindo, untuk menyimpan arti kosakata bahasa Jawa atau bahasa Indonesia.

D. Pengumpulan Bahan (Material Collecting)

Peneliti melakukan metode pengumpulan bahan yang diperlukan untuk memenuhi kebutuhankebutuhan dalam pembuatan aplikasi ini. Metode itu adalah studi kepustakaan, wawancara dan kuesioner.

Bahan yang diperlukan untuk membangun aplikasi ini, baik berupa file-file gambar, animasi, teks, audio diperoleh dari berbagai sumber dan sebagian yang lain dibuat sendiri oleh peneliti.

E. Pembuatan (Assembly)

a. Layout dan Desain

Tahapan desain meliputi setiap halaman yang ada di aplikasi ini.

1) Halaman Intro

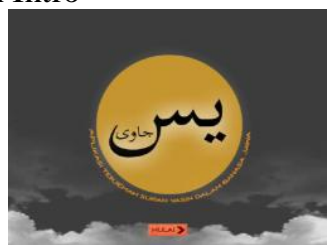

Gambar 2. Printscreen Halaman Intro

2) Halaman Menu Utama

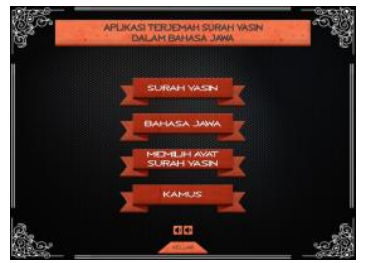

Gambar 3. Printscreen Halaman Menu Utama

3) Halaman Surah Yasin 


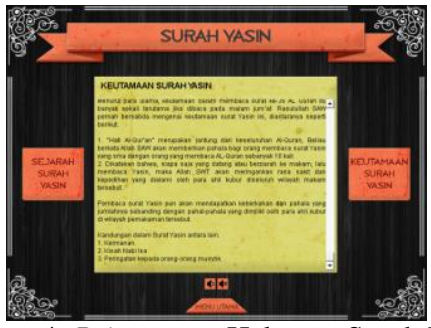

Gambar 4. Printscreen Halaman Surah Yasin

4) Halaman Bahasa Jawa

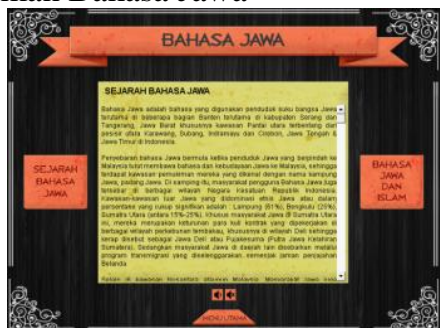

Gambar 5. Printscreen Halaman Bahasa Jawa

5) Halaman Memilih Ayat Surah Yasin

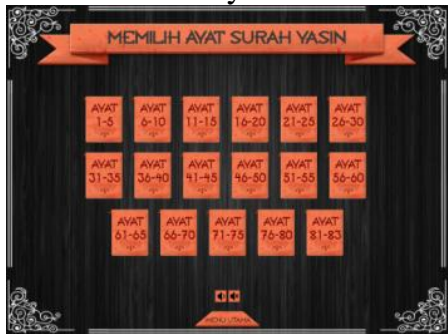

Gambar 6. Printscreen Halaman Memilih Ayat Surah Yasin

6) Halaman Terjemahan Surah Yasin

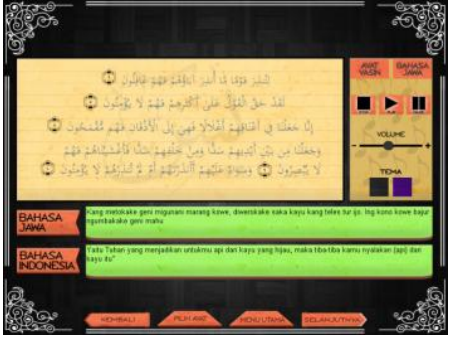

Gambar 7. Printscreen Halaman Terjemahan Surah Yasin

7) Halaman Kamus

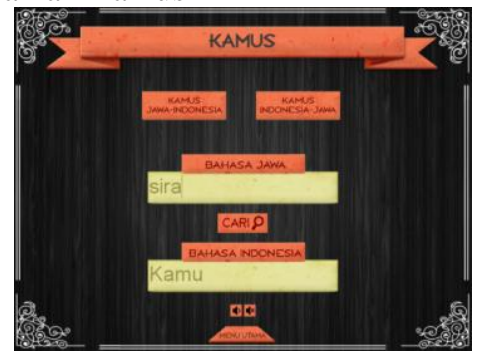

Gambar 8. Printscreen Halaman Kamus

b. Pembuatan Database Terjemahan Ayat Surah Yasin

1) Menjalankan software Arca Database Browser.

2) Membuat database baru dengan nama "dbterjemahyasin", kemudian buat table dengan nama "terjemahyasin" dan masukkan field name id, terjemahyasinjawa, terjemahyasinindo.
3) Pada field name id pilih tipe integer primary key, sedangkan pada field name terjemahyasinjawa dan terjemahyasinindo pilih tipe text.

4) Memasukkan data berupa terjemahan ayat bahasa Jawa dan bahasa Indonesia ke dalam field terjemahyasinjawa dan terjemahyasinindo sesuai dengan id nya.

5) Setelah semua data sudah dimasukkan, simpan database dengan format dat.

c. Pengkodingan

1) Terjemahan Surah Yasin

- Nama Script: panggildatabase

- Nama Script: panggilayat

2) Halaman Kamus

- Nama Script: panggildatabase

- Nama Script: panggilkamus,

- Nama Script: panggilkamus2

F. Pengujian (Testing)

Pengujian dilakukan untuk memeriksa fungsifungsi dalam aplkasi terjemahan surah Yasin ke dalam bahasa Jawa ini agar dapat berjalan dengan baik dan sesuai dengan perancangan yang telah disusun sebelumnya.

Pengujian aplikasi ini menggunakan jenis uji black-box, yaitu pengujian yang berfokus pada persyaratan fungsional perangkat lunak seperti pengujian tampilan dan pengujian fungsi.

G. Distribusi (Distribution)

Setelah aplikasi selesai dibuat, tahap selanjutnya adalah mendistribusikan hasil aplikasi ini melalui :

1. Kementerian Agama Republik Indonesia

Dengan memberikan DVD yang berisi aplikasi terjemahan surah Yasin ke dalam bahasa Jawa.

2. Upload

Di upload ke internet melalui website file sharing seperti www.4shared.com, www.mediafire.com dan www.ziddu.com.

A. Kesimpulan

Dari pembahasan yang telah diuraikan peneliti dapat menyimpulkan bahwa bahasa pemrograman Lingo dapat digunakan untuk membuat aplikasi multimedia dengan memberikan pengkodingan pada setiap obyek multimedia. Script Lingo juga dapat diintegrasikan dengan database terjemahan ayat surah Yasin ke dalam bahasa Jawa dengan bantuan software Arca Database Browser.

Dan pendistribusian aplikasi dilakukan dengan cara menyerahkan hasil aplikasi kepada Kementerian Agama Republik Indonesia untuk didistribusikan ke masyarakat dan peneliti mengunggah aplikasi di website file sharing agar dapat diunduh secara gratis.

B. Saran

a. Perlu dilakukan penambahan database surah lainnya yang terdapat dalam Al-Qur'an selain surah Yasin dan database kosakata kamus pada aplikasi ini. 
b. Perancangan aplikasi berbasis smartphone sangat dianjurkan agar menambah mobilitas pengguna.

c. Perlu dilakukan penambahan informasi berupa tafsir dalam terjemahan ayat untuk memperjelas maksud ayat yang terdapat dalam aplikasi.

\section{REFERENSI}

Andi, Rihanto. 2010. 100 Trik Rahasia Desainer Grafis, Yogyakarta: Wahana Komputer.

Arifin dkk. 1987. Tipe-tipe Kalimat Bahasa Jawa. Jakarta: Departemen Pendidikan dan Kebudayaan Republik Indonesia.

Binanto, Iwan. 2010. Multimedia Digital - Dasar Teori dan Pengembangannya. Yogyakarta: Penerbit Andi.

Departemen Agama Republik Indonesia. 2000. Kitab Al-Quran dan Terjemahannya. Jakarta.

Departemen Agama Republik Indonesia. 2004. Modul Al Quran dan Terjemahan Bahasa Jawa (36. Yaasiin). Jakarta.

Guritno, Suryo, Sudaryono, Rahardja, Untung. 2011. Theory and Application of IT Research Metodologi Penelitian Teknologi Informasi. Yogyakarta: Penerbit Andi

Hariyanto, Bambang. 2004. Rekayasa Sistem Berorientasi Objek. Bandung: Penerbit Informatika.

Hendratman, Hendi. 2011. The Magic of Macromedia Director. Bandung: Penerbit Informatika.

Luther, C Arc. 1994. Multimedia Authoring Interactive. Boston: AP Professional.

Nazir, M. 2005. Metode Penelitian. Jakarta: Ghalia Indonesia.

Pressman, Roger S. 2012. Rekayasa Perangkat Lunak (Edisi Bahasa Indonesia). Yogyakarta: Penerbit Andi.

Purnama, Bambang. 2013. KonsepDasar Multimedia. Yogyakarta: GrahaIlmu.

Pusat Bahasa Departemen Pendidikan Nasional. 2002. Kamus Besar Bahasa Indonesia (Edisi III). Jakarta: Balai Pustaka.

Rustan, Surianto. 2009. Layout Dasar dan Penerapannya, Jakarta: Gramedia Pustaka Utama.

Sasangka, Sry Satriya Tjatur Wisnu. 1991. Prinsipprinsip Dasar Berbahasa Jawa Ngoko dan Krama. Surabaya: Citra Jaya Murti.

Subana ,Sudrajat. 2005. Dasar-DasarPenelitian Ilmiah. Bandung: Pustaka Setia.

Sunyoto, Andi. 2010. Adobe Flash $+X M L=$ Rich Multimedia Application. Yogyakarta: Penerbit Andi.

Sutopo, Ariesto. 2003. Multimedia Interaktif dengan Flash. Yogyakarta: Graha Ilmu.

Syihab, M. Quraish dkk. 2001. Sejarah dan 'Ulum Al Quran. Jakarta: Pustaka Firdaus.

Vaughan, Tay. 2006. Multimedia: Making It Work (Edisi Bahasa Indonesia). Yogyakarta: Penerbit Andi.

www.bps.go.id, diakses pada tanggal 24 September 2014, pukul 20.14 www.kemenag.go.id, diakses pada tanggal 4 September 2014, pukul 13.58

www.xtras.tabuilero.com, diakses pada tanggal 19 Agustus 2014, pukul 22.02 